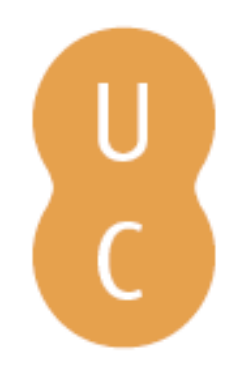

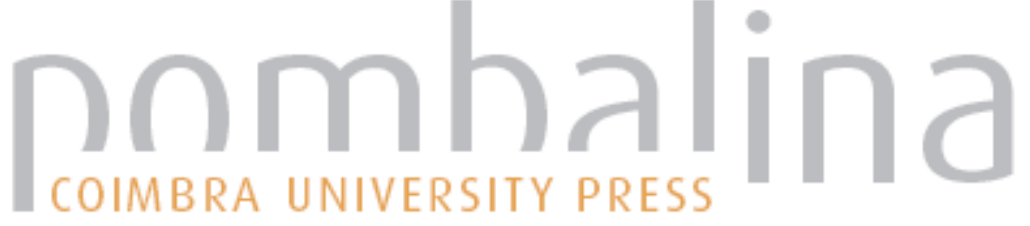

\section{A evolução da Engenharia no Rio de Janeiro de 1765 a 1810}

Autor(es): $\quad$ Piva, Teresa

Publicado por: Imprensa da Universidade de Coimbra

URL

persistente: URI:http://hdl.handle.net/10316.2/38446

DOI: $\quad$ DOI:http://dx.doi.org/10.14195/978-989-26-0764-1_10

Accessed : $\quad$ 26-Apr-2023 04:43:58

A navegação consulta e descarregamento dos títulos inseridos nas Bibliotecas Digitais UC Digitalis, UC Pombalina e UC Impactum, pressupõem a aceitação plena e sem reservas dos Termos e Condições de Uso destas Bibliotecas Digitais, disponíveis em https://digitalis.uc.pt/pt-pt/termos.

Conforme exposto nos referidos Termos e Condições de Uso, o descarregamento de títulos de acesso restrito requer uma licença válida de autorização devendo o utilizador aceder ao(s) documento(s) a partir de um endereço de IP da instituição detentora da supramencionada licença.

Ao utilizador é apenas permitido o descarregamento para uso pessoal, pelo que o emprego do(s) título(s) descarregado(s) para outro fim, designadamente comercial, carece de autorização do respetivo autor ou editor da obra.

Na medida em que todas as obras da UC Digitalis se encontram protegidas pelo Código do Direito de Autor e Direitos Conexos e demais legislação aplicável, toda a cópia, parcial ou total, deste documento, nos casos em que é legalmente admitida, deverá conter ou fazer-se acompanhar por este aviso.

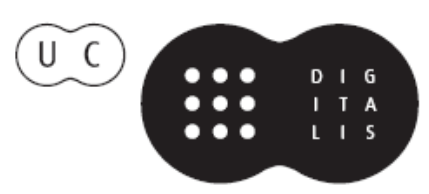


Universidade Federal do Rio de Janeiro

teresa.piva@yahoo.com.br

A EvoluÇão da Engenharia no Rio de Janeiro de 1765 a 1810

Teresa Piva

Muito pouco se escreveu sobre a Real Academia de Artilharia, Fortificação e Desenho, fundada em 1792, no Rio de Janeiro, por D. José Luís de Castro (1744-1819), 2. ${ }^{\circ}$ Conde de Rezende, Vice-Rei no período de 1790 a 1801. A Real Academia de Artilharia, Fortificação e Desenho foi antecessora da Academia Joanina de 1810. Foi neste período que surgiram as primeiras agremiações científicas do país, fundadas pelo beneplácito de sucessivos governantes ilustrados, o Marquês do Lavradio e D. Luis de Vasconcelos. O ambiente deste intervalo de tempo mostra a evolução em relação à época de José Fernandes Pinto Alpoim (1700-1765) e António Gomes Freire de Andrade (1685 -1763), 1. ${ }^{\circ}$ Conde de Bobadela.

O objetivo desta pesquisa foi investigar o processo de evolução do estudo e aplicação da engenharia no Rio de Janeiro no período que medeia entre a morte de Alpoim (1765) e a fundação da Academia Real Militar pelo Regente D. João VI (1810).

Pouco se tem estudado sobre a evolução da engenharia neste período aqui tratado. É por isso bastante oportuno fazê-lo, uma vez que este foi um período crucial que antecedeu àquele que viu o Rio de Janeiro tornar-se a sede da corte e capital do Império português. As atividades aqui desenvolvidas foram importantes para afastar definitivamente o risco de conquistas e aventuras de corsários ou esquadras estrangeiras, bem como continuar o trabalho de desenvolvimento urbano iniciado no tempo de Alpoim.

Esta investigação se baseou, sobretudo, em fontes documentais originais existentes em arquivos, bibliotecas de instituiçôes civis e militares do Brasil e de Portugal, além da utilização de fontes bibliográficas secundárias.

A REAl aCADEMIA DE ARTILHARIA, FORTIFICAÇÃo E DESENHO: OS PRIMÓRDIOS

D. Maria I (1734-1816), Rainha de Portugal no período de 1777 a 1816, instituiu por uma Carta de Lei datada de 2 de janeiro de 1790 a Academia Real de Fortificação, Artilharia e Desenho (ARFAD), em Lisboa. Um artigo publicado em outubro de 2006, na Revista Militar de Portugal, considerou a ARFAD a primeira escola autenticamente científica destinada ao ensino superior com a finalidade de formar oficiais do Exército português (BORGES e CANAS 2006). 
A Real Academia de Artilharia, Fortificação e Desenho, criada no Brasil em 1792, teve como modelo a ARFAD, e o objetivo de seu curso era formar oficiais para o Exército Português na colônia (CARUSO 2008).

Esta preocupação em haver similaridade na formação dos quadros do exército português na metrópole e na colônia já vinha desde 1767 .

A idéia de ter pessoas qualificadas para defender o Brasil é bem anterior a criação da Real Academia de Artilharia, Fortificação e Desenho. A época de Alpoim, os governantes portugueses tinham conhecimento da extensão do litoral brasileiro, a produção de açúcar, as descobertas auríferas e de diamantes em Minas Gerais e da quantidade insuficiente de embarcações de guerra para patrulhar a costa da colônia, foram alguns fatores que exigiram um permanente controle de Portugal nas fronteiras da Metrópole na primeira metade do século XVIII.

As invasões francesas no Rio de Janeiro, em 6 de agosto de 1710 por Jean François Duclerc (1671-1711) e em setembro de 1711 por René Duguay-Trouin (1673-1736) criaram um clima de terror na cidade e geraram um clima de insegurança e fragilidade nas tropas brasileiras. Os governantes solicitaram ao Rei de Portugal trabalhos de fortificação para que se resguardassem melhor as fronteiras do Brasil.

A situação da época gerou um desafio para Portugal: fornecer uma estrutura militar terrestre ao Brasil na época da colonização, e por este motivo a Coroa Portuguesa decidiu criar uma forma possível de ensinar ciências, técnicas de fortificação e matemática em escolas especializadas, capacitando homens para defender a Colônia.

O custo operacional de Portugal para enviar e manter no Brasil profissionais estrangeiros competentes nos trabalhos de fortificaçôes era muito alto e a solução encontrada foi enviar professores e criar escolas que formassem pessoas qualificadas no serviço de guerra na Colônia.

Os primórdios da Real Academia de Artilharia, Fortificação e Desenho se reportam às aulas ministradas no Terço de Artilharia, uma unidade militar criada pela Ordem Régia de 19 de agosto de 1738, exigindo que todo oficial militar para ser promovido ou nomeado deveria estar aprovado nas Liçōes da Aula.

Foi esta mesma Ordem Régia que nomeou e promoveu o engenheiro militar José Fernandes Pinto Alpoim (1700-1765), ao posto de Sargento-Mor, posto extinto, que atualmente se equivale ao posto de Major. Alpoim, além de comandar o Terço de Artilharia, tinha a função de lente do dito Terço, ministrando a Aula do Terço, sendo seu legado ensinar a técnica da artilharia. Deveria também deixar registradas as suas aulas em forma de apostila, uma vez que não existiam livros que discorressem sobre o assunto nos moldes necessários para as suas aulas (Decreto / Ordem Régia - 19 de Agosto de 1738, ARQUIVO NACIONAL).

José Fernandes Pinto Alpoim ao escrever os livros não só deixou registrados seus ensinamentos, mas esta também criou uma forma de facilitar o aprendizado. Os livros Exame de Artilheiros, de 1744, e Exame de Bombeiros, de 1748, foram escritos no Brasil, porém, impressos em Lisboa e Madri, respectivamente, sendo considerados os dois primeiros livros de Matemática escritos no Brasil. Embora seja isto o que está escrito nos frontispícios, há dúvidas se o local de impressão do segundo livro teria mesmo sido em Madrid, considerando a secular inimizade entre Espanha e Portugal. Por que se imprimiria em Madrid um livro repleto de 
revelações estratégicas sobre a capital do Vice-Reino? A menção a Madrid pode ter sido posta para desviar a atenção, na hipótese de o livro ter sido impresso no Rio de Janeiro.

A obra Exame de Artilheiros é composta de três partes: o Tratado de Aritmética, o Tratado de Geometria e o Tratado de Artilharia. O terceiro tratado possui ainda quatro apêndices, totalizando 259 páginas. A forma empregada na apresentação textual é baseada em quase sua totalidade no método de perguntas e respostas que foram elaboradas e respondidas pelo próprio autor.

Paulo Pardal, ao fazer a análise crítica do Exame de Artilheiros, reconheceu a importância histórica da obra na cultura técnica do Brasil, enfatizando, todavia que a matemática utilizada no livro era elementar, tendo em vista que a finalidade do mesmo era servir de instrumento para a prática de técnicos de artilharia (PARDAL 1987).

O Exame de Bombeiros é uma continuação do primeiro livro de Alpoim, Exame de Artilheiros, mas neste caso a matemática foi utilizada com maior rigor que no livro anterior. No decorrer da obra Alpoim se refere diversas vezes a seu primeiro trabalho.

O Exame de Bombeiros, que possui 444 páginas, é composto por dez tratados, a saber: Geometria, uma "nova" Trigonometria, Longimetria, Altimetria, Morteiros, Morteiros Pedreiros, dos Obus, dos Petardos, Baterias de Morteiros, e de Pyrobolia Militar. Neste livro Alpoim deixou registrado que seus alunos, mesmo com as dificuldades da época, não eram tão limitados intelectualmente como na época do inglês Francisco Malto, que escreveu no livro Prática da Guerra que no seu tempo (século XVII) os bombeiros não sabiam fazer uso das bombas. Alpoim considerou que seus alunos aprendiam o que hoje denominamos de balística elementar, onde os corpos lançados ao ar apresentam uma trajetória, uma linha, parabólica. (ALPOIM 1748, p. 143)

Exame de Bombeiros é um livro formado por perguntas e respostas como o Exame de Artilheiros, contudo é dedicado ao preparo dos artilheiros que desejassem trabalhar com bombas. Os livros de Alpoim foram um marco inicial no ensino da engenharia militar do Brasil, em especial da engenharia militar.

Alpoim lecionou na Aula do Terço até a sua morte, e quem o sucedeu nesta tarefa foi o Capitão Eusébio Antonio de Ribeiro, conforme determina a carta de D. Antonio Rolim de Moura Tavares (1709-1782), Conde de Azambuja ao provedor da Fazenda Real, datada de 02 de janeiro de 1768: "falecendo Alpoim, sucedeu-lhe o capitão Eusébio Antonio Ribeiro” (Carta do Vice-Rei Conde de Azambuja, 1768).

Posteriormente, em 1774 , documento oficial datado de 15 de setembro registrou a vinda de Portugal do Capitão Antonio Joaquim de Oliveira, o cadete Caetano Pimentel e o Sargento-mor José Pereira Pinto, nomeados para serem professores do regimento de artilharia. Acrescentava ainda que deveria ser entregue ao Capitão os livros e instrumentos de matemática. (Correspondência da Corte de Portugal, 1774).

Ainda no ano de 1774 se acrescentou à Aula do Terço de Artilharia a disciplina de Arquitetura Militar e com isto o nome o nome da aula passou a ser Aula Militar do Regimento de Artilharia. Da continuidade desta aula militar surgiria a Real Academia de Artilharia, Fortificação e Desenho em 1792 (BARATA, 1973). 
A Real Academia de Artilharia, Fortificação e Desenho foi instalada na antiga Casa do Trem de Artilharia, conhecida apenas pelo nome de Casa do Trem, que se desenvolveu a partir do Forte de Santiago, na murada da Ponta do Calabouço, um dos pontos estratégicos para a defesa da cidade do Rio de Janeiro.

A Casa do Trem não foi idealizada e construída com o fim específico de ser uma edificação onde houvesse a atividade de ensino. A sua denominação indicava que se tratava de um local para armazenar, organizar e inventariar material de guerra. Seus objetivos eram bem definidos, como se pode observar pelos ensinamentos de Alpoim ao apresentar um método mais fácil de contar as bombas e balas nas pilhas: "Como nos Trens, se empilham as bombas e balas para ocuparem menos terreno e se lhe saber logo o número ..." (ALPOIM, 1748, p. 297)

Pirassinunga (1958, p. 33) relata que a antiga Casa do Trem era o depósito de material bélico da Artilharia portuguesa em meados do século XVIII.

O Governador Gomes Freire de Andrade, 1. ${ }^{\circ}$ Conde de Bobadela (1685-1763), foi quem ordenou em 1762 a construção da Casa do Trem, esta ordem foi registrada em uma pedra granítica sobre a porta principal da antiga Casa do Trem.

A tradução da inscrição foi feita por Winz:

“sendo rei dos Portugueses D. José Primeiro, que é exemplar dos reis e grandíssima honra do mundo. Esta casa foi construída para os soldados, no ano do Senhor de 1762 pelo Conde de Bobadella que a mandou erguer” (WINZ 1962, p. 93)

Não existe comprovação de o risco e a construção da Casa do Trem serem de autoria do engenheiro José Fernandes Pinto Alpoim, uma vez que não foi encontrada nenhuma documentação que comprovasse. O historiador Antonio Pimentel Winz relatou que encontrou algumas cartas do Conde da Cunha, que de forma deselegante, o Vice-rei criticava a obra do Brigadeiro Alpoim, acrescentado que suas edificaçóes eram frágeis e que Alpoim não tinha conhecimento para erguer uma parede no prumo (WINZ 1962).

Não se pode considerar este argumento, uma vez que Alpoim foi considerado um grande politécnico, um dos maiores engenheiros do século XVIII, exercendo várias atividades dentre elas a de militar, engenheiro, professor.

A hipótese presumida de ser de sua autoria o risco e construção da Casa do Trem, mesmo estando o Brigadeiro Alpoim com idade avançada foi decorrente da sua ligação pessoal com o Conde de Bobadela e do seu prestígio na época.

A arquitetura da edificação era simples, com dois corpos laterais mais avançados, cada um tendo três andares e duas janelas por andar; o corpo central com dois andares, com sete janelas no segundo pavimento e seis janelas e uma porta no andar térreo.

A Casa do Trem era uma edificação pequena de três pavimentos em linhas arquitetônicas retas e fachada equilibrada (WINZ 1962).

Em 1764 o Vice-Rei Antonio Álvares da Cunha (1700-1791), 1. ${ }^{\circ}$ Conde da Cunha reformou a Casa do Trem, edificando outro prédio ao lado esquerdo, o Arsenal do Trem. Este novo prédio era o Arsenal de Guerra, pois tinha a função de fabricar munição e consertar as armas das tropas da Colônia. 
Com a finalidade de consolidar normas para a nova academia, o Conde de Rezende criou os Estatutos da Real Academia de Artilharia, Fortificação e Desenho, que datam de 17 de Dezembro de 1792 e estão com a sua rubrica.

Em carta encaminhada ao Ministro Martinho de Melo e Castro, enviando os Estatutos da Academia, o Conde de Rezende relatava:

"Remeto a V. Exa. os Estatutos da nova Aula Militar que no dia 17 do presente mês, por ser o dos Anos de Sua Majestade, mandei abrir nesta Cidade, a qual assisti com um grande número de oficiais e concurso de muitas pessoas, que além dos matriculados, a quem com antecedência havia prevenido e feito avisar para assistirem a esse ato, poderão aproveitar-se dos Estudos da mesma Aula" (PIRASSINUNGA, 1958, p. 29).

Aurélio de Lyra Tavares afirmou que: "Joaquim Correia de Serra foi o inspirador da criação da Real Academia de Artilharia, Fortificação e Desenho da Cidade do Rio de Janeiro, na qual se transformou a Aula Militar do Regimento de Artilharia” (TAVARES 2000, p. 176).

Os Estatutos possuem nove artigos que comprovam que essa instituição se diferenciava das aulas dos cursos anteriores, pois possuía o caráter de um verdadeiro instituto de ensino superior, com organização comparável aos congêneres de sua época (TELES 1984).

O Artigo $1 .^{\circ}$ apresenta o Plano de Ensino do Curso e explica que se tratava de um Curso de Matemática e Exercícios práticos, com a duração de 6 anos para o curso completo, determinando ainda o conteúdo programático que se deveria ministrar em cada ano.

O Curso de Belidor a que se referem os estatutos são os ensinamentos do militar e engenheiro civil hispano-francês Bernard Forest Belidor (1698-1761), nascido na Catalunha, Espanha, que lecionou no período de 1720 a 1738 na Academia Militar de La Fère-en-Tardenois, e que se tornou conhecido por escrever manuais sobre fortificações, engenharia civil e balística, como Nouveau Cours de Mathématiques escrito em 1722 e publicado na França em 1725, La Science des Ingénieurs dans la conduite des travaux des fortifications et des bâtiments civils (1729-1734) e Nouvelle méthode pour jeter des bombes avec précision (1731) (VALENTE 1999).

O livro Nouveau Cours de Mathematique é composto por 643 páginas dividido em 14 partes as quais o autor chamou de "Livros". Possui partes teóricas e apresenta desenhos ilustrativos.

Pela primeira página do sumário da obra é possível conhecer alguns dos assuntos que eram estudados no primeiro "livro".

- Noções de Geometria, definições dos termos, operaçōes e reduções algébricas, adiçôes de termos algébricos complexos e não complexos, afirmaçôes matemáticas demonstradas através de teoremas, operaçôes com fraçôes, problemas matemáticos e explicações dos mesmos.

O Artigo $1 .^{\circ}$ dos Estatutos da Academia do Rio de Janeiro acrescenta ainda o que se deveria estudar no terceiro ano:

“(...) No terceiro ano se ensinará a teoria da Artilharia, das Minas e Contra-minas, e a sua aplicação ao ataque e defesa das Praças, o que se fará pela Doutrina de Sam Remy, na conformidade do 
Plano de Regimentos de Artilharia, ou (o que é o mesmo) pela Artilharia de Blond.(...)" (Art. 1. ${ }^{\circ}$ dos Estatutos da Real Academia de Artilharia, Fortificação e Desenho, 1792)

A Doutrina de Sam Remy (sic) a que se refere o fragmento do texto do Art. $1 .^{\circ}$ dos Estatutos são os ensinamentos do francês Pierre Surirey de Saint Remy (1645-1716), autor do livro Memoires d'Artillerie (1697), obra em dois volumes, que está dividida em quatro partes:

- A parte inicial é dedicada aos oficiais, os seus direitos, imunidades, privilégios e escolas.

- A segunda parte apresenta todos os tipos de armas como: pistolas, morteiros, armas, facas e ainda se refere aos seus respectivos projéteis.

- A terceira parte trata de ferramentas, pontes, minas, carros, técnicas de fabricação e componentes da pólvora.

- Na quarta parte, o autor se reporta aos arsenais e depósitos de armas, a composição de uma equipe e, finalmente, os direitos dos funcionários. As páginas finais do livro apresentam um um glossário com 184 pranchas muito detalhadas que ilustram os capítulos.

O conteúdo do livro era abrangente e foi utilizado durante muitos anos na formação de oficiais na artilharia francesa.

Já a expressão Artilharia de Blond também citada no texto trata-se dos estudos de Guillaume Le Blond (1704-1751), autor dos livros L'Artillerie Raisonnée contenant l'usage des différentes bouches à feu (1761) e Traité de L'attaque des places (1780), Éléments de fortification (1786).

O livro L'Artillerie Raisonnée está dividido em 23 capítulos.

Ao analisar os ensinamentos transmitidos aos alunos da academia, é possível perceber que muitos destes assuntos já eram ensinados por Alpoim aos seus alunos e estes ensinamentos foram deixados escritos por ele nas obras Exame de Bombeiros e Exame de Artilheiros.

Exigia-se dos alunos um mínimo de conhecimentos para que se tornassem oficiais militares do Exército nas armas de Infantaria e de Cavalaria, para tanto, teriam que cursar os 3 primeiros anos da academia.

Os alunos, para se tornarem oficiais na arma da Artilharia eram mais exigidos, deveriam cursar cinco anos e teriam que ter os seguintes ensinamentos:

“(...) No quarto ano se ensinará a Fortificação regular, o ataque e defesa das Praças e os princípios fundamentais de qualquer fortificação. No quinto ano se ensinará a Fortificação irregular, a Fortificação efetiva e a Fortificação de Campanha, no que se seguirá a doutrina no Curso de Antoni, cuja instrução dos ditos cinco anos será dada pelo Lente do Regimento de Artilharia desta Cidade" (Art. 1. ${ }^{\circ}$ dos Estatutos da Real Academia de Artilharia, Fortificação e Desenho, 1792).

As aulas nos cinco primeiros anos eram ministradas pelo professor do Regimento de Artilharia da guarnição no Rio de Janeiro, tal como na época de Alpoim, em que o próprio comandante do Terço de Artilharia era o lente da Aula do Terço. 
Os alunos que cursassem até o quinto ano deveriam conhecer os ensinamentos do engenheiro militar Pedro Joaquim Xavier, que foi lente da Academia Real de Fortificação e Desenho de Lisboa. Pedro Xavier escreveu em Lisboa o livro Arquitectura militar de Antoni, baseada na obra Arquitectura militar originalmente escrita em italiano, por Alessandro D’Antoni (1714-1786). A obra de Pedro Xavier, composta de seis volumes, serviu de referência por muitos anos para a Academia Real de Fortificação Artilharia e Desenho local em que lecionava (SILVA 1858).

Finalmente os oficiais da arma de Engenharia teriam que cursar seis anos.

Apenas um professor ensinava no último ano, porém deveria ser nomeado pelo Rei de Portugal ou indicado pelo vice-rei do Brasil (PIRASSINUNGA 1958).

Era no último ano que os alunos cursavam as disciplinas específicas da engenharia civil conforme a determinação do Artigo 2..$^{\circ}$ do seu Estatuto.

O nome do livro em que os alunos do sexto ano estudavam hidráulica não foi citado nos Estatutos, mas ao ler o sumário da obra de Bernard Forest Belidor, Architecture Hydraulique, escrita em 1750 é possível conhecer alguns dos assuntos que se estudavam na época. A obra de Belidor possui 585 páginas, e foi dividida em 6 partes que por sua vez foram subdivididos em vários capítulos, possuindo ainda muitas ilustrações.

$\mathrm{O}$ Artigo $3 .^{\circ}$ dos Estatutos refere-se especificamente aos professores.

O primeiro lente da Real Academia de Artilharia, Fortificação e Desenho foi o Coronel Antonio Joaquim de Oliveira, militar português, enviado ao Brasil em 1774, com a finalidade de ser lente de arquitetura militar na aula do Regimento de Artilharia (OLIVEIRA 2005).

Os lentes auxiliares do Coronel Antonio Joaquim de Oliveira foram o Capitão de Artilharia José de Oliveira Barboza e o Capitão Antonio Lopes de Barros, primeiro e segundo substitutos respectivamente (PIRASSINUNGA 1958).

As atividades práticas determinavam que os professores acompanhassem os alunos nos procedimentos no campo sempre que as condiçōes do tempo estivessem favoráveis. Estes exercícios práticos iniciavam a partir do 2. ${ }^{\circ}$ ano, como se pode verificar nos Estatutos.

O terceiro ano exigia-se a prática específica para o manejo das armas de fogo.

As aulas práticas no $4 .^{\circ}$ ano visavam a estratégia militar:

As atividades práticas dos $5 .^{\circ}$ e $6 .^{\circ}$ anos se dedicavam aos acampamentos militares.

O Artigo $5 .^{\circ}$ dos Estatutos previa a forma de avaliação a ser aplicada aos alunos e em adição definia as exigências para a promoção a cada ano de estudos.

Os exames eram feitos na presença do professor, mediante o sorteio de pontos previamente selecionados. Não foi especificado se as provas deveriam ser orais ou escritas nem se deveriam ser efetuadas a portas fechadas ou publicamente. $\mathrm{O}$ aluno teria vinte e quatro horas para se preparar para o exame após o sorteio dos pontos que seriam argüidos.

Esta forma de avaliação privilegia a memória, e pelo tipo de prova percebe-se que o ensino científico era descritivo e livresco, e as questões exigidas dos alunos poderiam não ter originalidade por parte dos professores.

Para a admissão dos alunos na Academia era feita uma verificação da competência dos conhecimentos matemáticos e exigia-se a aptidão da Língua Francesa, uma vez que os livros que utilizavam eram de autores franceses, provavelmente os melhores da época.

Exigia-se ainda para que os alunos desejassem seguir a profissão de Engenheiros que os mesmos tivessem aptidão para o desenho. 
A exigência da exatidão nos traçados dos desenhos já se fazia na época das Aulas do Terço, como se pode observar pela página do Tratado de Geometria no livro Exame de Artilheiros, escrito por Alpoim em 1744.

O período letivo e o de descanso, o horário para as aulas e atividades escolares também foram previstos nos Estatutos. A carga horária exigida dos alunos era substancial e pouco tempo sobrava para o período de férias. Portugal sempre foi um país que cultuava a religião cristã e transmitiu esta devoção aos brasileiros da época, uma vez que respeitavam os períodos considerados sagrados para a religião católica, como o Natal, a Semana Santa, a Semana da Páscoa.

Os concludentes da Academia que completassem os 6 anos tornavam-se oficiais Engenheiros e seus destinos eram determinados segundo a sua aplicação e indicação dos seus Lentes. O Vice-rei proporia a nomeação dos mesmos a Sua Majestade.

Os alunos que desejassem se tornar oficiais das armas de Infantaria, Cavalaria e Artilharia teriam os seus locais de atuação determinados mediante as suas aplicações no curso e eram propostos pelos seus chefes, não sendo levados em consideração os Estatutos de 1790 e o que ordenava o Plano dos Regimentos de Artilharia, que levavam em conta a antiguidade.

A Academia necessitava de uma estrutura administrativa e os Estatutos previam as funçôes e obrigaçôes dos mesmos.

O Capitão Domingos Francisco Ramos foi secretário quando ainda estudava na Academia (PIRASSINUNGA 1958).

A aprovação e freqüência dos alunos eram controladas através de um livro de registros, guardado no arquivo e sua atualização era de responsabilidade do secretário e deveriam ser rubricados pelos professores. Os desenhos, projetos e plantas elaborados pelos alunos também eram arquivados.

A segurança, asseio das aulas e limpeza dos modelos e instrumentos utilizados nas atividades práticas ficavam a cargo de um porteiro e de guardas.

Em 1793, no primeiro ano do funcionamento da Academia, o efetivo era de 73 alunos, a maioria militares. O Coronel Adailton Pirassinunga relacionou os nomes dos alunos fundadores, porém não cita a sua fonte de consulta (PIRASSINUNGA 1958, pp. 35-38).

Existiam alunos "partidistas" o que hoje se denomina bolsista, observando-se que a Academia incentivava os alunos a seguirem a profissão de engenheiro.

Saber desenhar era uma habilidade de suma importância e considerado um conhecimento fundamental para o exercício da profissão militar. Os mapas eram raros e os existentes continham informações incorretas sobre formatos, localizações e distâncias. Tanto o desenho a mão livre quanto o geométrico assumiram papel de destaque para o conhecimento e a defesa do território brasileiro.

Ao analisar os Estatutos verificou-se que muitos dos artigos influenciaram outras instituições criadas posteriormente, como por exemplo, a Escola Polytechica, criada em 1874. De acordo com o Artigo 9. ${ }^{\circ}$ dos Estatutos desta Escola, os desenhos, plantas e demais trabalhos dos alunos também deveriam ser arquivados.

Encontram-se no acervo do Museu da Escola Politécnica da Universidade Federal do Rio de Janeiro, diversos trabalhos de alunos da Escola Polytecnica, comprovando que esta prática ocorrera.

Outro exemplo de instituição que seguiu os Estatutos da Real Academia de Artilharia, Fortificação e Desenho foi o Imperial Colégio Militar, criado em 1889 no Rio de Janeiro. 
Os alunos para serem promovidos se submetiam a uma banca examinadora e os conteúdos que deveriam ser cobrados eram selecionados previamente, numerados e sorteados 24 horas antes do exame os pontos que deveriam ser abordados, tal qual o que orientava o artigo 5..$^{\circ}$ dos Estatutos da Real Academia de Artilharia, Fortificação e Desenho.

\section{A FORMAÇÃo DE OUTRA ACADEMIA}

Havia uma insatisfação na Academia do Rio de Janeiro por parte dos alunos oficiais das armas de Infantaria e Cavalaria, pois os mesmos tinham a determinação do local de atuação determinado mediante a sua aplicação no curso, não sendo levados em consideração os Estatutos de 1790 e o que ordenava o Plano dos Regimentos de Artilharia, que levavam em conta a antiguidade. Em adição havia desinteresse dos cadetes de Infantaria nos conteúdos de desenho, fortificação e conhecimentos específicos de artilharia. Para tanto, houve uma ramificação no ano de 1795, e outra academia foi criada com a finalidade de habilitar os oficiais de Infantaria. Ficando ambas em funcionamento.

Em 26 de novembro de 1795 o Conde de Rezende enviou para Lisboa os estatutos da Nova Academia de Aritmética, Geometria Prática, Fortificação, Desenho e Lingua Francesa..

O próprio texto do estatuto considerava que esses alunos antes se achavam "sem os princípios necessários para servirem de base a lição dos Autores e a acertada execução das diferentes operaçôes militares".

Os estudos nessa Academia tinham a duração de um ano e meio. Nos primeiros seis meses se estudava a Aritmética, no semestre seguinte a Geometria Prática e, nos últimos seis meses, os Elementos de Fortificação pelo livro de Le Blond. Os estudos de Desenho e Língua Francesa duravam os dezoito meses.

Em carta dirigida a D. Luiz Pinto de Souza, o Conde de Rezende assim expôs sobre essa nova Academia:

"Quanto às ciências julguei que seria por agora bastante a Aritmética de Bezout, a Geometria de Belidor, a Fortificação, o Desenho e a Língua Francesa; omitindo-se, porém nestas ciências aquilo que elas tem de mais abstrato, em atenção à falta de luzes e de princípios que tinha a maior parte dos discípulos" (PIRASSINUNGA 1958, pp. 49-50).

Esta nova academia iniciou suas atividades contando com o efetivo de 16 discentes, entre eles dois filhos do Conde de Resende: o Sargento Mor, D. Luiz Inocêncio Benedito de Castro (1777-1824) que posteriormente se tornou o $3^{\circ}$ Conde de Resende e o Capitão D. José Benedito de Castro (1780-?) (PIRASSINUNGA 1958).

Não se tem certeza, até o momento, se essa Academia também funcionava na Casa do Trem. No entanto, é interessante considerar que as suas aulas se realizavam, segundo seu Estatuto, as terças, quintas e sábados pela manhã. Por sua vez, as aulas da Real Academia de Artilharia, Fortificação e Desenho ocorriam também por força estatutária, nas segundas, quartas e sextas pela manhā. Isto permite se conjecturar que as duas academias conviviam na Casa do Trem, provavelmente utilizando as mesmas salas.

Adailton Pirassinunga apresenta, ao final do seu livro, a transcrição de um interessante relato prestado pelos Lentes dessa Academia sobre o desempenho dos seus alunos, datado de 1798 . 
Até os dias de hoje, a historiografia relativa a essas duas Academias é rara. Pode-se afirmar que a Academia de Aritmética, Geometria Prática, Fortificação, Desenho e Língua Francesa funcionou, pelo menos, até 1800. Nesse ano, o Conde de Rezende encaminhou para Portugal informações sobre o Capitão Albino dos Santos Pereira. No texto da sua carta ele informa que o Capitão Albino "é lente de Geometria na Aula instituída no ano de 1795 ”. O verbo no tempo presente indica o funcionamento da Academia até 1800 (PIRASSINUNGA 1958, p.54)

Já em relação à Real Academia de Artilharia, Fortificação e Desenho, esta funcionou, como se considerou inicialmente, até a criação da Academia Real Militar em 4 de dezembro de 1810. No entanto, pouco se sabe o que nela ocorreu na primeira década dos oitocentos. Mesmo assim, podem ser citados, pelo menos, dois fatos significativos que ocorreram nessa Academia. O primeiro refere-se à nomeação, pelo decreto de 30 de maio de 1809, de Eduardo Thomaz Cohill como "... lente da Cadeira da língua ingleza na Academia Militar desta Corte". O teor do decreto determinava que o seu serviço fosse imediato, “... devendo, enquanto não se abrirem as aulas da mesma Academia, principiar as suas lições no local que lhe for indicado pelo Tenente General de Artilharia Inspector Geral da mesma arma...”. A expressão “enquanto não se abrirem as aulas da mesma Academia” estaria-se referindo à futura Academia Real Militar? Não parece ter sentido essa hipótese, pois a Academia Real Militar só foi instituída bem mais tarde, um ano e meio depois dessa nomeação. Além disso, em meados de 1809, a Academia Real Militar não estava sequer embrionada.

A nomeação do General Napion para proceder a reorganização do ensino militar, no que resultou a Academia Real Militar, só foi determinada pelo Conde de Linhares em princípio de 1810 , seis meses após o Decreto de 30 de maio de 1809. Essas considerações acentuam a fragilidade da hipótese considerada. Nesse sentido, deve-se pensar que o decreto se referia à Real Academia de Artilharia, Fortificação e Desenho. Aliás, o título do decreto é imperativo: Crêa a cadeira de língua ingleza na Academia Militar desta Côrte. Faz sentido a criação da referida cadeira, pois a mesma não estava prevista no Estatuto de 1792.

O segundo fato a ser levado em consideração foi a criação, pelo Decreto de 6 de julho de 1810, de uma cadeira de química na Academia Militar. Por esse decreto, Daniel Gardner, Membro da Sociedade Filosófica e Matemática de Londres, foi nomeado para "... promover ... o estudo da chimica, particularmente nas aulas militares de Artilharia e Engenharia...”.

Embora em 6 de julho de 1810 a constituição da Academia Real Militar já estivesse sendo elaborada pelo General Napion, o que resultou no Título Segundo do Estatuto a possibilidade de que "... a Junta poderá propor que se estabeleçam Professores da Língua ... Ingleza...", a expressão no decreto "nas aulas militares de Artilharia e Engenharia", refere-se à Real Academia de Artilharia, Fortificação e Desenho. Em primeiro lugar porque nela não havia a cadeira de química.. Mas, o que é mais forte, o pagamento ao professor retroagia a “... 1..$^{\circ}$ de julho do corrente ano...” e, mais ainda, o professor receberia um “... ordenado de $600 \$ 000$ dos quaes $100 \$ 000$ se entenderão destinados a fazer as despezas do Curso ...". Isto significa que o curso já estaria em funcionamento, ou prestes a começar.

É interessante observar que esses decretos nomearam como Lentes dois professores ingleses, provavelmente devido à influência política que a Inglaterra tinha sobre a Corte portuguesa na primeira década dos anos 1800 . 
Em 1810, D. Rodrigo de Souza Coutinho, o Conde de Linhares, instituiu a Academia Real Militar, sucedendo a Real Academia de Artilharia, Fortificação e Desenho e absorvendo seus alunos. A aula inaugural da Academia Real Militar foi realizada em 23 de abril de 1811, nas salas da Casa do Trem.

\section{Conclusão}

A vinda a Corte Portuguesa para o Brasil exigiu muitas mudanças, dentre elas a criação da Academia Real Militar por D. João VI em 1810. Mesmo extinta a Real Academia de Artilharia, Fortificação e Desenho deixou marcas em diversas outras instituições de ensino.

A Casa do Trem foi um marco no processo de formação dos oficiais militares e dos engenheiros brasileiros. Aliada dos fortes e fortalezas por ser o local de guarda e organização do material bélico, constituiu-se também em uma casa de ensino.

A Casa do Trem sediou a Real Academia de Artilharia, Fortificação e Desenho, a mais antiga instituição de ensino militar da qual se tem conhecimento dos estatutos, professores, alunos, regime escolar. Nas suas salas os alunos obtinham os conhecimentos necessários para defender o território brasileiro, tais como a teoria da Artilharia, das Minas e Contra-minas, o ataque e defensa das Praças, a Fortificação regular e de campanha. E pode-se acrescentar que os que ali estudaram aprenderam a construir obras de caráter civil, como a arquitetura civil, o corte de pedras e madeiras, o orçamento das edificações, os caminhos e calçadas, as pontes e os canais, portos, diques e comportas.

Com este trabalho percebeu-se o os ensinamentos do Brigadeiro Alpoim não foram em vão, o Rio de Janeiro jamais voltaria a ser tomado e ocupado por estrangeiros, conseguiu-se fortalecer as defesas da cidade. O governo do Conde de Bobadela e, sobretudo, a ação multifacetada de seu lugar-tenente, Alpoim, tiveram papel fundamental nessa mudança.

Alpoim conseguiu o seu objetivo: passar a seus camaradas e discípulos, de que só pelo conhecimento e aplicação da ciência e da técnica se poderia desenvolver e consolidar um sistema de defesa eficaz e consoante às necessidades de seu tempo.

\section{REFERÊNCIAS}

ALPOIM, José Fernandes Pinto - Exame de Artilheiros: que compreende Arithmetica, Geometria e Artilharia. Lisboa: Oficina de Jozé Antonio Plates, 1744.

ALPOIM, José Fernandes Pinto - Exame de Bombeiros. Madri: Officina de Francisco Martinez, 1746.

Arquivo Nacional. Ordem Régia 19 de agosto de 1738. Catálogo de cartas régias (1662-1821). Rio de Janeiro, I, p. 472.

Arquivo Nacional. Estatutos da Real Academia de Artilharia, Fortificação e Desenho, da Cidade do Rio de Janeiro. Datado de 17 de dezembro de 1792. Rio de Janeiro. Coleção de Memórias. V. 12.

Arquivo Nacional. Carta do Vice-Rei Conde de Azambuja ao Provedor da Fazenda Real. 02de janeiro de 1768. Catálogo de cartas. Rio de Janeiro. Cod. 61, v. 23, fl. 208.

Arquivo Público Nacional. Correspondência da Corte de Portugal com o Vice-Rei do Brasil. Rio de Janeiro, período de 1763 a 1808 , fls. 125 verso, liv. 3, copia.

BARATA, Mario - Escola Politécnica do Largo de São Francisco: berço da engenharia militar brasileira. Rio de Janeiro: Associação Antigos Alunos da Politécnica [etc.], 1973.

BELIDOR, Bernard Forest - Architecture Hydraulique. Paris: Chez Jombert, Libraire du Roi, pour l'Artillerie \& Génie, rue Dauphine, 1750. 
BELIDOR, Bernard Forest - Nouveau Cours de Mathematique. Paris: Chez Jombert, Libraire du Roi, pour l'Artillerie \&Génie, rue Dauphine, 1757.

BORGES, João Jorge Botelho Vieira; CANAS, António José Duarte Costa - Uma Cronologia da História do Ensino Superior Militar em Portugal. Revista Militar [Em linha]. Jan. (2010) [Consult. 10 Jan. 2010] Disponível em http://www.revistamilitar.pt/modules/content/index.php?id=5

CARUSO, Ernesto - Ponta do Calabouço início do século xx Berço Fardado dos Doutores. Revista do Clube Militar. Rio de Janeiro: [s.n.]. ano LXXXI (Ago/Set/Out.), no 430 (2008).

LE BLOND, Guillaume - Traité de L'Attaque des Places. Paris: Rue Dauphine, Chez L. Cillot, Gendre\& Suceffeur de M Jombert Libr. \& Impr. pour L'Arrillerie \& le Génie, second Porte Cochere à droit par le Pont-Neuf, 1780.

LE BLOND, Guillaume - L'Artillerie Raisonnée contenant l'usage des différentes bouches à feu. Paris: Chez Charl Ant Jombert Librarire du Roi, pour l'Artillerie \& Génine, Rue Dauphine, à l'Image Notre-Dame, 1761.

MOREIRA, Heloi José Fernandes - A Escola Politécnica da UFRJ. In REDE DA MEMÓRIA VIRTUAL BRASILEIRA. Ciências [Em linha]. Brasil: Biblioteca Nacional, 2008. [Consult. 23 Jan. 2010] Disponível em WWW:<URL:http://bndigital.bn.br/projetos/redememoria/poli.html.>

OLIVEIRA, João Carlos de - D. João VI, adorador do Deus das ciências: A Constituição da Cultura Científica no Brasil (1808-1821). Rio de Janeiro: E-Papers.

PARDAL, Paulo - Memórias da Escola Politécnica. Rio de Janeiro: UFRJ [etc.], 1984.

PARDAL, Paulo - BRASIL 1792: Início do Ensino da Engenharia Civil e da Escola de Engenharia da UFRJ. [S.I.]: Construtora Norberto Odebrecht SA, 1985.

PIRASSINUNGA, Adailton Sampaio - O Ensino Militar no Brasil - período Colonial. [S.l.]: Biblioteca do Exército Editora, 1958.

TAVARES, Aurélio de Lyra - A Engenharia Militar Portuguesa na Construção do Brasil. Rio de Janeiro: Biblioteca do Exército Editora, 2000.

TELES, Pedro Carlos da Silva - História da Engenharia no Brasil - Séculos XVI a XIX. Rio de Janeiro: LTD, 1984.

SAINT RÉMY, Pierre Surirey de - Mémoires d'Artillerie. Paris: Chez Jean Anisson, Directeor de I'mprimerier Royal, Rue de la Hape, à la Fleur de Lis de Florence, 1697.

SILVA, Innocéncio Francisco da - Dicionario Bibliographico Portuguez: estudos de Innocéncio Francisco da Silva aplicáveis a Portugal e ao Brazil. Lisboa: Imprensa Nacional, 1858.

SOUZA, Augusto Fausto - Fortificaçôes no Brasil. Revista do IHGB. Rio de Janeiro: Typographia Universal de Laemmert \& C. 16, 2 (1858).

VARNHAGEN, Francisco Adolfo de - História Geral do Brazil. Madri: Imprensa de V. de Dominguez, 1854. p. $337-338$.

WINZ, Antonio Pimentel - A História da Casa do Trem. Rio de Janeiro: Museu Histórico Nacional, 1962. 